\title{
Triplet-State and Singlet Oxygen Formation in Fluorene-Based Alternating Copolymers
}

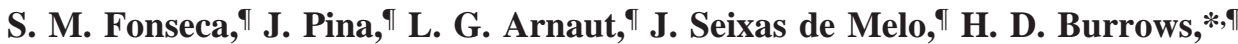 \\ N. Chattopadhyay, ${ }^{\S}$ L. Alcácer, ${ }^{\#}$ A. Charas, ${ }^{\#}$ J. Morgado, ${ }^{\#}$ A. P. Monkman, U. Asawapirom, ${ }^{\ddagger}$ \\ U. Scherf, ${ }^{¥}$ R. Edge, ${ }^{\perp, \|}$ and S. Navaratnam ${ }^{\perp, \mathfrak{x}}$ \\ Departamento de Química, Universidade de Coimbra, 3004-535 Coimbra, Portugal, Department of Chemistry, \\ Jadavpur University, Calcutta 700 032, India, Instituto de Telecomunicações, Instituto Superior Técnico, \\ Av. Rovisco Pais, 1049-001 Lisbon, Portugal, Department of Physics, University of Durham, \\ Durham DH1 3LE, U.K., Makromolekulare Chemie, Bergische Universität Wuppertal, \\ D-42097 Wuppertal Germany, Free Radical Research Facility, Daresbury Laboratory, \\ Warrington, WA4 4AD, U.K., School of Physical and Geographical Sciences, Keele University, \\ ST5 4BG, U.K., and Biosciences Research Institute, University of Salford, M4 4WT, U.K.
}

Received: January 13, 2006; In Final Form: March 13, 2006

\begin{abstract}
Data are reported on the triplet states of a series of fluorene-based A-alt-B type alternating copolymers based on pulse radiolysis-energy transfer and flash photolysis experiments. From the pulse radiolysis experiments, spectra are given for eight copolymers involving phenylene, thiophene, benzothiadiazole, and oligothienylenevinylene groups. Quantum yields for triplet-state formation $\left(\Phi_{\mathrm{T}}\right)$ have been obtained by flash photolysis following laser excitation and in one case by photoacoustic calorimetry. In addition, yields of sensitized formation of singlet oxygen have been determined by time-resolved phosphorescence and are, in general, in excellent agreement with the $\Phi_{\mathrm{T}}$ values. In all cases, the presence of thiophene units is seen to increase intersystem-crossing quantum yields, probably because of the presence of the heavy sulfur atom. However, with the poly[2,7-(9,9-bis(2'-ethylhexyl)fluorene)-alt-1,4-phenylene] (PFP), thiophene S,S-dioxide (PFTSO2) and benzothiadiazole (F8BT) copolymers, low yields of triplet formation are observed. With three of the copolymers, the energies of the triplet states have been determined. With PFP, the triplet energy is virtually identical to that of poly[2,7-(9,9-bis(2'-ethylhexyl)fluorene)]. In contrast, with fluorene-thiophene copolymers $\mathrm{PFaT}$ and PF3T, the triplet energies are closer to those of thiophene oligomers, indicating that there is significant conjugation between fluorene and thiophene units but also that there is a more localized triplet state than with the homopolymers.
\end{abstract}

\section{Introduction}

Conjugated organic polymers now represent an important class of materials, with applications ranging from light-emitting diodes to sensors, photovoltaic systems, and thin-film transistors. ${ }^{1,2}$ Some of these devices have already reached the stage of commercialization, whereas others are at fairly advanced stages of development.

Polyfluorenes are currently some of the most widely studied conjugated copolymers for such applications because they possess high fluorescence quantum yields, good stability, are available with high degrees of purity, and also emit in the blue region of the spectrum. ${ }^{3-9}$ In addition, they can form liquid crystalline structures, giving the possibility of producing polarized luminescence. ${ }^{10,11}$

There is currently considerable interest in tuning these emission properties and in modifying charge injection barriers

* Corresponding author. E-mail: burrows@ci.uc.pt. Address: Departamento de Química, Universidade de Coimbra, 3004-535 Coimbra, Portugal. Tel: $+351+239854482$. Fax: $+351+239827703$.

II Universidade de Coimbra.

$\S$ Jadavpur University.

\# Instituto Superior Técnico.

$\doteqdot$ University of Durham.

¥ Bergische Universität Wuppertal.

$\perp$ Daresbury Laboratory.

" Keele University.

${ }^{£}$ University of Salford. and transport by copolymerization of fluorene with other conjugated molecules. A number of experimental ${ }^{5,12-41}$ and theoretical ${ }^{42-45}$ studies have been reported on both random and alternating fluorene copolymers, and it has been found that by copolymerization with thiophene units it is possible to tune the emission through the visible region, in addition to modulating the HOMO and LUMO levels for charge injection. ${ }^{7}$ Particularly important in this respect are alternating copolymers, and the synthesis and fluorescence properties of a series of derivatives of the type A-alt-B have been reported, where $\mathrm{A}$ is a 9,9dialkylfluorene group (particularly the diethylhexyl derivative) and $\mathrm{B}$ is phenyl, thiophene, terthiophene, or thiophene-S,Sdioxide. ${ }^{17,21,25,28}$ With these copolymers, the photoluminescence quantum yields were lower when thiophene groups are present than in the corresponding phenyl-9,9-dialkylfluorene copolymers. This was attributed to enhanced intersystem crossing to the lowest triplet states in the former case due to the presence of sulfur, in agreement with the observation of triplet-state formation being much more important with polythiophenes than with polyfluorenes. ${ }^{46,47}$ Other important moieties for these alternating copolymers include the benzothiadiazole group, as in poly(9,9-dioctylfluorene-co-benzothiadiazole) (F8BT), ${ }^{15,30,33}$ and oligothienylenevinylene ${ }^{17,39}$ unit, as in PFBTVT (Figure 1).

However, despite the large number of studies on synthesis, spectroscopy, and photophysics of fluorene-based copolymers, little information is available on their triplet states. Apart from 

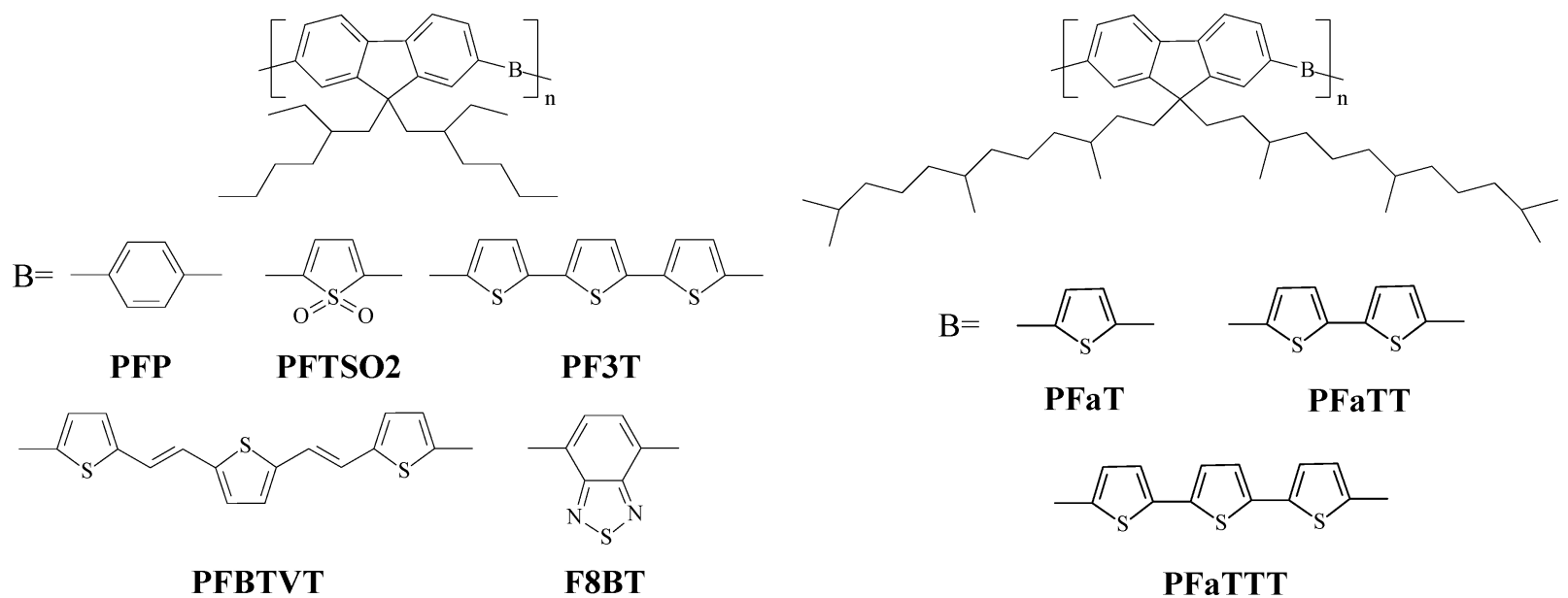

PFBTVT

F8BT

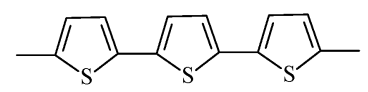

PFaTTT

Figure 1. Molecular structures of the various polyfluorene copolymers used in this study.

TABLE 1: Photophysical Properties of the Various Polyfluorene Copolymers in Benzene

\begin{tabular}{|c|c|c|c|c|c|c|c|c|}
\hline copolymer & $\begin{array}{c}M_{\mathrm{n}} / M_{\mathrm{w}} \\
\left(\langle n\rangle^{i}\right)\end{array}$ & $\begin{array}{c}T-T_{\max } \\
(\mathrm{nm}) \\
\left(\epsilon_{\mathrm{T}}\left(\mathrm{M}^{-1} \mathrm{~cm}^{-1}\right)\right)\end{array}$ & $\begin{array}{c}E_{\mathrm{S}_{1}}(\mathrm{eV}) \\
\left(\epsilon_{\mathrm{S}}^{h}\left(\mathrm{M}^{-1} \mathrm{~cm}^{-1}\right)\right)\end{array}$ & $\Phi_{\mathrm{F}}^{a}$ & $\Phi_{\mathrm{T}^{a}}^{a}$ & $\Phi_{\mathrm{IC}^{a}}^{a}$ & $\begin{array}{c}\tau_{\mathrm{T}} \\
(\mu \mathrm{s})\end{array}$ & $\Phi_{\Delta}^{a}$ \\
\hline $\mathrm{PFaT}$ & $\begin{array}{c}8790 / 13600 \\
(13)\end{array}$ & $\begin{array}{c}760^{b} \\
\left(72200^{c}\right)\end{array}$ & $\begin{array}{c}2.69 \\
(23800)\end{array}$ & 0.568 & 0.258 & 0.174 & 5 & 0.254 \\
\hline PFaTT & $\begin{array}{c}11100 / 20800 \\
(15)\end{array}$ & $\begin{array}{c}760^{b} \\
\left(75650^{c}\right)\end{array}$ & $\begin{array}{c}2.55 \\
(32100)\end{array}$ & 0.377 & 0.319 & 0.304 & 1.2 & 0.272 \\
\hline PFaTTT & $\begin{array}{c}12800 / 24400 \\
(15)\end{array}$ & $\begin{array}{c}760^{b} \\
\left(23200^{c}\right)\end{array}$ & $\begin{array}{c}2.40 \\
(34800)\end{array}$ & 0.293 & 0.166 & 0.541 & 2 & 0.164 \\
\hline PF3T & $\begin{array}{c}2800 / 4200 \\
(4)\end{array}$ & $\begin{array}{c}730^{b} \\
\left(49900^{f}\right)\end{array}$ & $\begin{array}{c}2.48 \\
(48700)\end{array}$ & $0.37^{d}$ & $0.335^{f}$ & 0.295 & 10 & $0.32^{f}$ \\
\hline PFBTVT & $5300 / 18500(8)$ & $\begin{array}{c}640^{a} \\
\left(9500^{b}\right)\end{array}$ & $\begin{array}{c}2.47 \\
(13100)\end{array}$ & 0.0965 & 0.179 & 0.724 & 5 & 0.16 \\
\hline F8BT & $\begin{array}{c}\text { n.d. } \\
(-)\end{array}$ & $\begin{array}{c}760^{b} \\
\left(12000^{c}\right)\end{array}$ & $\begin{array}{c}2.53 \\
(28500)\end{array}$ & 0.760 & & & & 0.074 \\
\hline PFTSO2 & $\begin{array}{c}8700 / 27400 \\
(17)\end{array}$ & $\begin{array}{l}580^{b} \\
(-)^{g}\end{array}$ & $\begin{array}{c}2.39 \\
(14900)\end{array}$ & 0.190 & & & 124 & 0.0108 \\
\hline PFP & $\begin{array}{c}12700 / 50230 \\
\text { (27) }\end{array}$ & $\begin{array}{c}730^{c} \\
\left(82000^{c}\right)\end{array}$ & $\begin{array}{c}3.16 \\
(52700)\end{array}$ & $\sim 1^{e}$ & 0.0081 & & 134 & 0.0225 \\
\hline
\end{tabular}

${ }^{a} \Phi_{\mathrm{F}}, \Phi_{\mathrm{T}}, \Phi_{\mathrm{IC}}$, and $\Phi_{\Delta}$ are quantum yields for fluorescence, triplet formation, internal conversion, and sensitized singlet oxygen formation, respectively. ${ }^{b}$ From flash photolysis data. ${ }^{c}$ From pulse radiolysis data. ${ }^{d}$ Reference $21{ }^{e}$ Reference $25 .{ }^{f}$ Reference $37 .{ }^{g}$ Not determined. ${ }^{h}$ In terms of monomer unit. ${ }^{i}$ Average number of monomer units per polymer chain, that is, $M_{\mathrm{n}} / \mathrm{MWt}$.

one study by optically detected magnetic resonance (ODMR), ${ }^{31}$ and our initial report on the characterization of the properties of the triplet state of poly[2,7-(9,9-bis(2'-ethylhexyl)fluorene)alt-2,5-terthiophene] (PF3T), ${ }^{37}$ we are unaware of any other work on triplets of these copolymers. This is an important omission for various reasons. Triplet-state formation in conjugated polymer systems is a mixed blessing. On the positive side, it can be used to optimize emission yields through electrophosphorescent devices. ${ }^{48}$ In contrast, in the presence of oxygen, triplet states can lead to singlet oxygen formation and ultimately device degradation. ${ }^{49}$ Also, conjugated polymer triplet states may quench the emission of phosphorescent dopants. ${ }^{50} \mathrm{We}$ have, therefore, characterized the triplet states of some of the most important members of this class of materials in terms of their spectra, intersystem-crossing formation yields, and decay kinetics using a combination of pulse radiolysis and flash photolysis. In addition, their efficiency in sensitizing singlet oxygen formation has been studied using time-resolved phosphorimetry. With representative copolymers, we have also measured the triplet-state energies using either the pulse radiolysis-energy transfer technique ${ }^{51-53}$ or time-resolved photoacoustic calorimetry. ${ }^{37,47,54,55}$

\section{Experimental Section}

The structures and abbreviations of the polymers used in this study are shown in Figure 1, and weight and number average molecular weights are presented in Table 1. Details of synthesis are given elsewhere. ${ }^{19,25}$ All reagents were of the purest grades available, and solvents were purified by standard procedures. Except where stated, all photophysical measurements were made on benzene solutions, degassed by bubbling with argon or nitrogen.

Pulse radiolysis experiments were carried out at the Free Radical Research Facility, Daresbury, U.K. using $200 \mathrm{~ns}-2 \mu \mathrm{s}$ high energy electron pulses from a $12 \mathrm{MeV}$ linear accelerator, which were passed through solutions in a $2.5 \mathrm{~cm}$ optical path length quartz cuvette attached to a flow system. All solutions were bubbled with argon for about 30 min before experiments. The experimental setup has been described elsewhere. ${ }^{56}$ Optical spectra, normalized for the radiation dose, were recorded using a spectrometer consisting of a xenon arc lamp, monochromator, photomultiplier, and appropriate filters. Signals were then directed to a computer for analysis. The general spectrometer design is similar to that given in ref 57. Triplet states were generated by pulse radiolysis of argon-saturated solutions of 
copolymer (typically $30 \mathrm{mg} / \mathrm{L}$, corresponding to $\leq 10 \mu \mathrm{M}$ in terms of polymer) and biphenyl $(10 \mathrm{mM})$ in benzene. Tripletstate molar absorption coefficients were determined using the method of Bensasson and Land ${ }^{51}$ using argon-saturated solutions of biphenyl $(10 \mathrm{mM})$ in benzene as standard, taking the value $\epsilon=27100 \mathrm{M}^{-1} \mathrm{~cm}^{-1}$ at $367 \mathrm{~nm}$ for its triplet extinction coefficient.

Flash photolysis experiments were performed with an Applied Photophysics laser flash photolysis equipment pumped by the third harmonic (355 nm) of a Nd:YAG laser (Spectra Physics). Signals were detected with Hamamatsu IP28 and R928 photomultipliers, and transient spectra were obtained by monitoring the optical density change at 5-10 nm intervals over the 300$850 \mathrm{~nm}$ range, averaging at least 10 decays at each wavelength. Further details have already been given. ${ }^{58}$ Spectra were assigned to the triplet states based on the similarity with spectra seen in pulse radiolysis and the fact that first-order kinetics were observed in all cases. The triplet formation quantum yield $\left(\Phi_{\mathrm{T}}\right)$ was obtained by comparing the initial absorbance of an optically matched solution (at the laser wavelength) of the copolymer ${ }^{60}$ with that of a solution of benzophenone in benzene as actinometer $\left(\epsilon_{\mathrm{T}}=7630 \mathrm{M}^{-1} \mathrm{~cm}^{-1}\right.$, and $\left.\Phi_{\mathrm{T}}=1.00\right){ }^{51,59}$ Absorption and fluorescence spectra were recorded on Shimadzu UV-2100 and Jobin-Yvon Spex Fluorog 3-2.2. spectrophotometers. Fluorescence spectra were corrected for the wavelength response of the system. Fluorescence quantum yields were determined using terthiophene $\left(\Phi_{\mathrm{F}}=0.07\right)^{46}$ and pentathiophene $\left(\Phi_{\mathrm{F}}=0.34\right)^{46}$ in benzene as standards.

Singlet oxygen $\left({ }^{1} \Delta_{\mathrm{g}}\right)$ yields and lifetimes were obtained by direct measurement of the phosphorescence at $1270 \mathrm{~nm}$ following irradiation of an aerated solution of the polymers in benzene with a frequency-tripled pulse $(355 \mathrm{~nm})$ from a $\mathrm{Nd}$ : YAG laser, as described in detail elsewhere. ${ }^{47,61}$ The quantum yield of singlet oxygen formation was determined by comparison of the initial emission intensity for optically matched solutions at the excitation wavelength $\left(\mathrm{A}_{355}=0.5\right)$ with $1 H$-phenalen1-one taken as standard, using $\Phi_{\Delta}=0.93$ in benzene solution. ${ }^{62}$

Time-resolved photoacoustic calorimetry (PAC) measurements were performed on a home-built apparatus with frontface irradiation, using a nitrogen laser $(337 \mathrm{~nm})$ for excitation. Heat deposition was within a time window of a few nanoseconds to a few microseconds. Details of experimental method and data analysis are given elsewhere..$^{47,55,63}$

\section{Results \& Discussion}

3.1. Spectral Characterization of the Triplet States. Radiolysis of benzene is known ${ }^{64}$ to lead to formation of both excited states and ions ${ }^{64,65}$ in the process

$$
\mathrm{Bz} \rightarrow{ }^{1} \mathrm{Bz}^{*}+{ }^{3} \mathrm{Bz}^{*}+\mathrm{e}_{\mathrm{s}}^{-}+\mathrm{Bz}^{\bullet+}
$$

The yields (given as $G$ values, which are the number of species produced per $100 \mathrm{eV}$ of absorbed radiation) are $\mathrm{G}\left({ }^{1} \mathrm{Bz} *\right)=1.6$, $\mathrm{G}\left({ }^{3} \mathrm{Bz} z^{*}\right)=4.2,{ }^{66} \mathrm{G}\left(\mathrm{e}_{\mathrm{s}}{ }^{-}\right)=\mathrm{G}\left(\mathrm{Bz}^{+}\right)=0.053 .{ }^{67,68}$ In the absence of appropriate sensitizers, pulse radiolysis of benzene solutions of conjugated polymer systems can produce both excited states ${ }^{64,65}$ and radical ions (positive and negative charge carriers). ${ }^{69,70}$ However, upon pulse radiolysis of argon-saturated 10 $\mathrm{mM}$ solutions of biphenyl in benzene, the only significant species seen by transient absorption spectroscopy within the time resolution of our system was the biphenyl triplet state. This was unambiguously identified by comparison with literature spectra. ${ }^{51}$ On this basis, we find that triplet states of conjugated organic polymers and copolymers (S) can be selectively

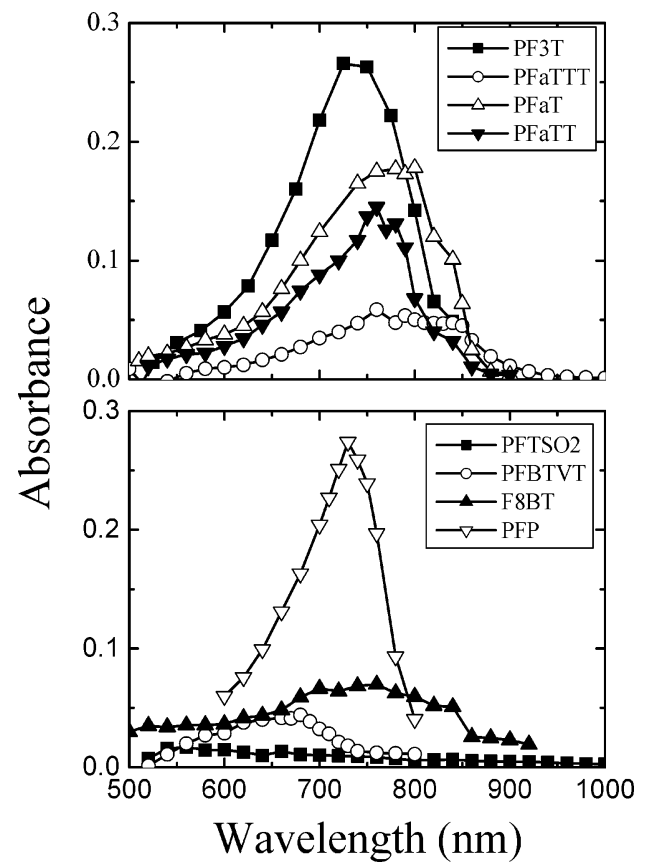

Figure 2. Transient absorption spectra observed on pulse radiolysis of argon-saturated solutions of the various polyfluorene copolymers in benzene in the presence of biphenyl $(10 \mathrm{mM})$.

produced by pulse radiolysis of benzene solutions in the presence of relatively high concentrations of biphenyl (or other sensitizers, A) followed by energy transfer ${ }^{51-53}$ in the reaction sequence

$$
\begin{gathered}
{ }^{1} \mathrm{Bz}^{*} \rightarrow{ }^{3} \mathrm{Bz}^{*} \\
{ }^{1} \mathrm{Bz}^{*}+\mathrm{A} \rightarrow \mathrm{Bz}+{ }^{1} \mathrm{~A}^{*} \\
{ }^{1} \mathrm{~A}^{*} \rightarrow{ }^{3} \mathrm{~A}^{*} \\
{ }^{3} \mathrm{Bz}^{*}+\mathrm{A} \rightarrow \mathrm{Bz}+{ }^{3} \mathrm{~A}^{*} \\
{ }^{3} \mathrm{~A}^{*}+\mathrm{S} \rightarrow \mathrm{A}+{ }^{3} \mathrm{~S}^{*}
\end{gathered}
$$

subject to the kinetically demanded concentration ratio $[\mathrm{Bz}] \gg$ $[\mathrm{A}] \gg[\mathrm{S}]$. This technique was applied, using biphenyl $(10 \mathrm{mM})$ as the sensitizer, to characterize the triplet states of all of these copolymers, and their spectra are shown in Figure 2. In support of this assignment, the spectra show significant differences from those of the corresponding copolymer charge carriers (studies in progress). For all of the copolymers, except PFBTVT and PFTSO2, absorption maxima were observed in the 730-760 $\mathrm{nm}$ region. This can be compared with the maxima observed for the triplet states of poly[2,7-(9,9-bis(2'-ethylhexyl)fluorene) $(\mathrm{PF} 2 / 6,750 \mathrm{~nm})^{52}$ and terthiophene $(645 \mathrm{~nm}) .{ }^{46,55}$ With PFT$\mathrm{SO} 2$, only a weak absorption was observed around $580 \mathrm{~nm}$, whereas with PFBTVT the triplet maximum was at $640 \mathrm{~nm}$. The fact that very similar triplet-triplet $(\mathrm{T}-\mathrm{T})$ absorption maxima are observed with the fluorene-thiophene alternating copolymers having one, two, and three thiophene units can be contrasted with the behavior of oligothiophenes, ${ }^{46,55,71}$ where a progressive increase in the $\mathrm{T}-\mathrm{T}$ absorption is observed on increasing the number of thiophene units. This strongly suggests that in the copolymers there is a relatively short effective conjugation length (strong localization) of the triplet states.

Triplet states were also studied by flash photolysis. As an example, following photoexcitation of PFaT in a degassed benzene solution with the third harmonic of a Nd:YAG laser $(355 \mathrm{~nm})$, depletion of ground-state absorption $(450 \mathrm{~nm})$, and 


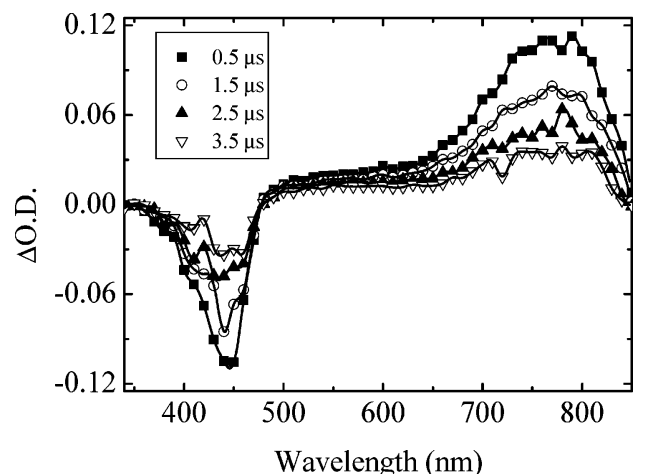

Figure 3. Triplet-singlet difference absorption spectra observed with different delays following laser excitation at $355 \mathrm{~nm}$ of a solution of $\mathrm{PFaT}$ in benzene.

formation of a new band at $760 \mathrm{~nm}$ was observed (Figure 3). This band at $760 \mathrm{~nm}$ is similar to that seen in pulse radiolysis and is assigned to the PFaT triplet state. It decayed exponentially with a lifetime of $\sim 4.9 \mu$ s. Similar transient absorptions were observed for many of the other copolymers, as indicated in Table 1. In some cases, depletion of ground-state absorption was observed in the 470-480 $\mathrm{nm}$ region. For PFBTVT, depletion of ground-state absorption occurred at $370 \mathrm{~nm}$, the triplet-state absorption was observed at $640 \mathrm{~nm}$, in agreement with the pulse radiolysis measurements, and the lifetime was $\sim 5.0 \mu \mathrm{s}$. The transient absorption spectra for PFTSO2 and PFP showed absorption bands at 580 and $430 \mathrm{~nm}$, respectively. With PFP, depletion of ground-state absorption was observed at $370 \mathrm{~nm}$. No depletion of ground-state absorption was observed for PFTSO2. With PFP, only very weak absorption was observed at the maximum $(730 \mathrm{~nm})$ seen in pulse radiolysis, suggesting inefficient intersystem crossing. The triplet-state lifetimes for PFTSO2 and PFP were, respectively, $\sim 124$ and $134 \mu \mathrm{s}$ (probably limited by impurity diffusion quenching), which are considerably larger than those for the other copolymers. The decrease in triplet lifetime with the thiophene copolymers is attributed to the heavy-atom effect of sulfur, which increases spin-orbit coupling and facilitates the intersystem crossing from excited triplet states to the singlet ground state, thus reducing their triplet lifetimes. ${ }^{47,72}$ Upon S,S-dioxide functionalization of the thiophene ring, that is, in going from PFaT to PFTSO2, there appears to be a significant increase in triplet lifetime. By removing the sulfur lone-pairs from the thienyl $\pi$ system, a decrease of sulfur spin-orbit coupling and an increase in triplet lifetime is expected and indeed observed. However, this result needs to be treated with caution because the observed transient is produced in very low yield and may not be a pure triplet state.

3.2. Energies of the Triplet States. Triplet energies of PFP and $\mathrm{PFaT}$ were obtained from pulse radiolysis-energy transfer by matching with the triplet energy of the sensitizer (A), as described elsewhere. ${ }^{52-54}$ For PF3T, the triplet energy was determined by time-resolved photoacoustic calorimetry, as discussed previously. ${ }^{37}$ Values for these compounds are compared with those for the conjugated oligomers and homopolymers in Table 2 and can be compared with the values of 2.30 $\mathrm{eV}$ for PF2/6, ${ }^{52} 2.86-2.18 \mathrm{eV}$ for oligofluorenes, ${ }^{73}$ and $1.93-$ $1.72 \mathrm{eV}$ for oligothiophenes. ${ }^{55,71}$ The $\mathrm{S}_{1}-\mathrm{T}_{1}$ separation in conjugated polymers is typically $0.7-0.8 \mathrm{eV} .^{52,74-77}$ The values observed in these copolymers are fairly similar, indicating very similar electron-electron correlations in the homopolymers and copolymers. ${ }^{52.77}$ This contrasts with the three oligothiophenes in the Table $(\alpha 3, \alpha 4, \alpha 5)$, where the singlet triplet splitting decreases with increasing chain length. ${ }^{55}$
TABLE 2: Triplet Energies of PFP, PFaT, and PF3T ${ }^{a}$

\begin{tabular}{ccc}
\hline compound & $E_{\mathrm{T}_{1}}(\mathrm{eV})$ & $\Delta E\left(\mathrm{~S}_{1}-\mathrm{T}_{1}\right)$ \\
\hline $\mathrm{PFP}$ & 2.32 & 0.84 \\
$\mathrm{PF} 2 / 6$ & $2.30^{b}$ & 0.92 \\
$\alpha 3$ & $1.93^{c}$ & $1.24^{c}$ \\
$\mathrm{PFaT}$ & 1.84 & 0.85 \\
$\mathrm{PF} 3 \mathrm{~T}$ & $1.84^{d}$ & 0.64 \\
$\alpha 4$ & $1.81^{c}$ & $1.05^{c}$ \\
$\alpha 5$ & $1.72^{c}$ & $0.97^{c}$
\end{tabular}

${ }^{a}$ For comparison the triplet energies of PF $2 / 6$ and of the oligothiophenes $\alpha 3, \alpha 4$, and $\alpha 5$ are also presented. ${ }^{b}$ Reference 52. ${ }^{c}$ Reference 55. ${ }^{d}$ Reference 37.

We have shown previously ${ }^{52}$ that the energy of the lowest triplet state of many conjugated homopolymers can be related to their $S_{1}$ energies by the empirical relationship

$$
\mathrm{T}_{1}=\left(1.13 \mathrm{~S}_{1}-1.43\right) \pm 0.25 \mathrm{eV}
$$

Values predicted from this (PFP, $2.14 \mathrm{eV}$; PFaT, $1.61 \mathrm{eV}$; PF3T, $1.37 \mathrm{eV}$ ) are close to, but slightly lower than, the experimental ones, which again supports the idea that although there is conjugation between the monomer units, the triplet states in these copolymers are relatively localized. Further indications that the triplet states are localized comes from the fact that the low molecular weight PF3T has a triplet energy similar to that of the higher molecular weight PFaT. This suggests that triplet energies are already saturated in PF3T (i.e., when the copolymers have $\leq 4$ monomer units).

3.3. Triplet-State and Singlet Oxygen Quantum Yields. Quantum yields for triplet-state formation $\left(\Phi_{\mathrm{T}}\right)$ were determined by flash photolysis using benzophenone as actinometer. Using these and fluorescence quantum yields $\left(\Phi_{\mathrm{F}}\right)$ determined here or in previous studies, ${ }^{25}$ we also determined the efficiencies of internal conversion and they are given in Table 1. As has been suggested previously, ${ }^{17,21}$ the low fluorescence quantum yields observed for the fluorene-thiophene copolymers seem to be due largely to the efficient intersystem crossing involving the heavy sulfur atom, as has been noted with polythiophenes. ${ }^{47,78}$ The differences in intersystem-crossing quantum yields with the fluorene-terthiophene copolymers involving the trimethyldodecyl (PFaTTT) and 2-ethylhexyl (PF3T) substituents at the 9 position on the fluorene rings is attributed to the fact that the latter compound has a bromo end-cap, which is expected to favor intersystem crossing through the heavy atom effect. ${ }^{79}$ It is particularly interesting to observe that with all of the copolymers containing thiophene units, the internal conversion quantum yield plays a significant role, which is in accordance with previous findings on related polythiophenes ${ }^{78}$ where substitution at the thiophene skeleton with alkyl or alkoxy groups has been shown to increase the coupling with rotational modes of the substituent side chains and thus increase the efficiency of the radiationless decay. This is in contrast with the behavior found for the thiophene oligomers $(n=1-7)$ where internal conversion is practically inactive. ${ }^{46,80}$ In the present case the substituent side chains are located in the (poly)fluorene groups, which again supports the extension of the delocalization to these units and thus to their influence in the photophysics of these copolymers. It is worthy of note that with PFaT and PFaTT, the decrease in $\Phi_{\mathrm{F}}$ is accompanied by increases in both $\Phi_{\mathrm{T}}$ and $\Phi_{\text {IC }}$, whereas somewhat more complicated behavior is observed with PFaTTT, where the decrease in $\Phi_{\mathrm{F}}$ is reflected by an increase in $\Phi_{\mathrm{IC}}$ and a decrease in $\Phi_{\mathrm{T}}$. The reason for this is not yet clear. As with other $p$-phenylenevinylene polymers, such as $\mathrm{MEH}-\mathrm{PPV},{ }^{47}$ internal conversion is the dominant decay 
pathway with the copolymer PFBTVT in solution, possibly because of torsional contributions to nonradiative relaxation. However, in contrast to MEH-PPV, intersystem crossing is an important pathway with PFBTVT and explains the much lower fluorescence quantum yield with this polymer ( $\Phi_{\mathrm{F}}$ : PFBTVT, 0.0965; MEHPPV ${ }^{47} 0.28$, benzene solution). As with the other thiophene copolymers, this is likely to arise from increased spin-orbit coupling involving the sulfur atom.

Singlet oxygen formation is frequently observed following photolysis of aerated solutions of conjugated polymers. ${ }^{47}$ This species can be produced by energy transfer from excited triplet states to molecular oxygen according to the reaction

$$
{ }^{3} \mathrm{~S} *+\mathrm{O}_{2}\left({ }^{3} \Sigma_{\mathrm{g}}^{-}\right) \rightarrow \mathrm{S}+\mathrm{O}_{2}^{*}\left({ }^{1} \Delta_{\mathrm{g}}\right)
$$

This process can be quantified through the direct observation of the phosphorescence of singlet oxygen at $1270 \mathrm{~nm}$ following excitation of aerated solutions of the copolymers in benzene with pulses from a frequency-tripled Nd:YAG laser $(355 \mathrm{~nm})$. From the initial phosphorescence intensity at $1270 \mathrm{~nm}$ as a function of laser intensity and comparison of the slope with that for $1-H$ phenalen-1-one in benzene as standard, it was possible to estimate quantum yields for singlet oxygen formation $\left(\Phi_{\Delta}\right)$. These are also given in Table 1 and compared with the values of $\Phi_{\mathrm{T}}$ obtained by flash photolysis. In general, the agreement is very good, indicating efficient energy transfer from the copolymer triplet state to molecular oxygen, and supporting the validity of this method ${ }^{47}$ for determining intersystemcrossing quantum yields in conjugated polymers. The exception to this behavior is with PFP where $\Phi_{\Delta}$ is, apparently, higher than $\Phi_{\mathrm{T}}$. However, with the low intersystem-crossing yields in this system, there is a significant degree of uncertainty on these values and particularly in the $\Phi_{\mathrm{T}}$ value.

\section{Conclusions}

We have studied triplet-state formation and intersystem crossing in an A-alt-B series of fluorene copolymers using flash photolysis and pulse radiolysis-energy transfer. Spectral, energetic, and lifetime data of these polymers in benzene solution, compared with those of the homopolymers, show a closely related behavior, with similar singlet-triplet separation and intersystem crossing being favored by incorporation of thiophene rings. However, the copolymers provide the advantage that they allow tuning of optoelectronic properties, thus favoring their application in many molecular electronic devices. A key new finding from this work is the role of dearomatization of the sulfur lone-pair electrons on ISC. By effectively removing the sulfur lone pair from the $\pi$ conjugation, little heavy atom perturbation of the $\pi$ electrons occurs, giving rise to low ISC and concomitantly higher singlet yields. Thus, if it is desirable to include thiophene moieties in the polymer backbone, using the SS-dioxide functionalization of the thiophene ring will prevent adverse singlet exciton quenching to the triplet manifold.

Acknowledgment. Pulse radiolysis experiments were carried out at the Free Radical Research Facility in the Synchrotron Radiation Department of the CLRC Daresbury Laboratory, Warrington, U.K., with the support of the European Commission through the "Improving Human Potential" Transnational Access to Major Research Infrastructures Contract HPRI-CT-200200183. We thank the Fundação para a Ciência e a Tecnologia (FCT) for the award of a postdoctoral fellowship (S.M.F., grant SFRH/BPD/14924/2004) and a Ph.D. studentship (J.P., grant SFRH/BD/18876/2004). We thank POCI, FCT, FEDER (POCI/
QUI/58291/2004), and GRICES/DST (Indo-Portuguese Research Collaboration) for further financial support.

\section{References and Notes}

(1) Friend, R. H.; Gymer, R. W.; Holmes, A. B.; Burroughes, J. H.; Taliani, C.; Bradley, D. D. C.; Dos Santos, D. A.; Bredas, J. L.; Logdlund, M.; Salaneck, W. R. Nature 1999, 397, 121.

(2) Forrest, S. R. Nature 2004, 428, 911.

(3) Ohmori, Y.; Uchida, M.; Muro, K.; Yoshino, K. Jpn. J. Appl. Phys., Part 2 1991, 30, L1941.

(4) Grell, M.; Bradley, D. D. C.; Long, X.; Chamberlain, T.; Inbasekaran, M.; Woo, E. P.; Soliman, M. Acta Polym. 1998, 49, 439.

(5) Bernius, M. T.; Inbasekaran, M.; O’Brien, J.; Wu, W. Adv. Mater. 2000, 12, 1737.

(6) Lieser, G.; Oda, M.; Miteva, T.; Meisel, A.; Nothofer, H.-G.; Scherf, U.; Neher, D. Macromolecules 2000, 33, 4490.

(7) Bernius, M. T.; Inbasekaran, M.; Woo, E.; Wu, W.; Wujkowski, L. J. Mater. Sci.-Mater. Electron. 2000, 11, 111.

(8) Leclerc, M. J. Polym. Sci., Part A: Polym. Chem. 2001, 39, 2867.

(9) Scherf, U.; List, E. J. W. Adv. Mater. 2002, 14, 477.

(10) Grell, M.; Knoll, W.; Lupo, D.; Meisel, A.; Miteva, T.; Neher, D.; Nothofer, H.-G.; Scherf U.; Yasuda, A. Adv. Mater. 1999, 11, 671.

(11) Grell, M.; Bradley, D. D. C.; Ungar, G.; Hill, J.; Whitehead, K. S. Macromolecules 1999, 32, 5810.

(12) Ranger, M.; Leclerc, M. Can. J. Chem. 1998, 76, 1571.

(13) Liu, B.; Yu, W.-L.; Lai, Y.-H.; Huang, W. Macromolecules 2000 , 33,8945 .

(14) Blondin, P.; Bouchard, J.; Beaupré, S.; Belletête, M.; Durocher, G.; Leclerc, M. Macromolecules 2000, 33, 5874.

(15) Ho, P. K. H.; Kim, J. S.; Burroughes, J. H.; Becker, H.; Li, S. F. Y.; Brown, T. M.; Cacialli, F.; Friend, R. H. Nature 2000, 404, 481.

(16) Morgado, J.; Moons, E.; Friend, R. H.; Cacialli, F. Adv. Mater. 2001, 13, 810 .

(17) Charas, A.; Morgado, J.; Martinho, J. M. G.; Alcácer, L.; Cacialli, F. Chem. Commun. 2001, 1216.

(18) Lévesque, I.; Donat-Bouillud, A.; Tao, Y.; D’Iorio, M.; Beaupré, S.; Blondin, P.; Ranger, M.; Bouchard, J.; Leclerc, M. Synth. Met. 2001, 122,79 .

(19) Asawapirom, U.; Güntner, R.; Forster, M.; Farrell, T.; Scherf, U, Synthesis 2002, 9, 1136.

(20) Cho, N. S.; Hwang, D.-H.; Lee, J.-I.; Jung, B.-J.; Shim, H.-K. Macromolecules 2002, 35, 1224.

(21) Charas, A.; Morgado, J.; Martinho, J. M. G.; Alcácer, L.; Cacialli, F. Synth. Met. 2002, 127, 251

(22) Pålsson, L.-O.; Wang, C.; Russell, D. L.; Monkman, A. P.; Bryce, M. R.; Rumbles, G.; Samuel, I. D. W. Chem. Phys. 2002, 279, 229.

(23) Tirapattur, S.; Belletête, M.; Drolet, N.; Bouchard, J.; Tanger, M.; Leclerc, M.; Durocher, G. J. Phys. Chem. B 2002, 106, 8959.

(24) Belletête, M.; Morin, J.-F.; Beaupré, S.; Leclerc, M.; Durocher, G. Synth. Met. 2002, 126, 43.

(25) Charas, A.; Morgado, J.; Martinho, J. M. G.; Alcácer, L.; Lim, S.

F.; Friend, R. H.; Cacialli, F. Polymer 2003, 44, 1843.

(26) Hou, Q.; Niu, Y. H.; Huang, W. B.; Yang, R. Q.; Yuan, M.; Cao, Y. Synth. Met. 2003, 135-136, 185 .

(27) Pasini, M.; Destri, S.; Porzio, W.; Botta, C.; Giovanella, U. J. Mater. Chem. 2003, 13, 807 .

(28) Charas, A.; Morgado, J.; Alcácer, L.; Martinho J. M. G.; Cacialli, F. Synth. Met. 2003, 137, 1039.

(29) Svensson, M.; Zhang, F.; Veenstra, S. C.; Verhees, W. J. H.; Hummelen, J. C. M.; Kroon, J. M.; Inganäs, O.; Andersson, M. R. Adv. Mater. 2003, 15, 988 .

(30) Fung, M. K.; Lai, S. L.; Tong, S. W.; Bao, S. N.; Lee, C. S.; Wu, W. W.; Inbasekaran, M.; O'Brien, J. J.; Lee, S. T. J. Appl. Phys. 2003, 94, 5763.

(31) De Ceuster, J. Doctorate Thesis, Universiteit Antwerpen, Belgium, 2003.

(32) Ravirajan, P.; Haque, S. A.; Durrant, J. R.; Poplavskyy, D.; Bradley, D. D. C.; Nelson, J. J. Appl. Phys. 2004, 95, 1473.

(33) Charas, A.; Morgado, J.; Alcácer, L.; Brogueira, P.; Cacialli, F. Synth. Met. 2004, 147, 275 .

(34) Cho, N. S.; Hwang, D.-H-; Jung, B.-J.; Oh, J.; Chu, H. Y.; Shim, H.-K. Synth. Met. 2004, 143, 277.

(35) Chen, B.; Wu, Y.; Wang, M.; Wang, S.; Sheng, S.; Zhu, W.; Sun, R.; Tian, H. Eur. Polym. J. 2004, 40, 1183.

(36) Vamvounis, G.; Schulz, G. L.; Holdcroft, S. Macromolecules 2004, 37, 8897.

(37) Burrows, H. D.; Arnaut, L. G.; Pina, J.; Seixas de Melo, J.; Chattopadhyay, N.; Alcácer, L.; Charas, A.; Morgado, J. Chem. Phys. Lett. 2005, 402, 197; 2005, 404, 414.

(38) Mallavia, R.; Montilla, F.; Pastor, L.; Velásquez, P.; Arredondo, B.; Álvarez, A. L.; Mateo, C. R. Macromolecules 2005, 38, 3185. 
(39) Morgado, J.; Charas, A.; Martinho, J. M. G.; Alcácer, L. Synth. Met. 2005, 154, 81.

(40) Lee, S.-J.; Gallegos, J. R.; Klein, J.; Curtis, M. D.; Kanicki, J. Synth. Met. 2005, 155, 1.

(41) Lee, J.; Cho, N. D.; Lee, J.; Lee, S. K.; Shim, H.-K. Synth. Met. 2005, 155, 73 .

(42) Cornil, J.; Gueli, I.; Dkhissi, A.; Sancho-Garcia, J. C.; Hennebicq, E.; Calbert, J. P.; Lemaur, V.; Beljonne, D.; Brédas, J. L. J. Chem. Phys. 2003, 118, 6615.

(43) Wang, J.-F.; Feng, J.-K.; Ren, A.-M.; Liu, X.-D.; Ma, Y.-G.; Lu, P.; Zhang, H.-X. Macromoleules 2004, 37, 3451.

(44) Poolmee, P.; Ehara, M.; Hannongbua, S.; Nakatsuji, H. Polymer 2005, 46, 6474 . 969.

(45) Yang, L.; Feng, J.-K.; Ren, A.-M. J. Comput. Chem. 2005, 26,

(46) Becker, R. S.; Seixas de Melo, J.; Maçanita, A. L.; Elisei, F. J. Phys. Chem. 1996, 100, 18683.

(47) Burrows, H. D.; Seixas de Melo, J.; Serpa, C.; Arnaut, L. G.; Monkman, A. P.; Hamblett, I.; Navaratnam, S. J. Chem. Phys. 2001, 115, 9601.

(48) Thompson, M. E.; Burrows, P. E.; Forrest, S. R. Curr. Opin. Solid State Mater. Sci. 1999, 4, 369.

(49) Scurlock, R. D.; Wang, B.; Ogilby, P. R.; Sheats, J. R.; Clough, R. L. J. Am. Chem. Soc. 1995, 117, 10194.

(50) Sudhaker, M.; Djurovich, P. I.; Hogen-Esch, T. I.; Thompson, M. E. J. Am. Chem. Soc. 2003, 125, 7796.

(51) Bensasson, R. V.; Land, E. J. Trans. Faraday Soc. 1971, 67, 1904.

(52) Monkman, A. P.; Burrows, H. D.; Hartwell, L. J.; Horsburgh, L. E.; Hamblett, I.; Navaratnam, S. Phys. Rev. Lett. 2001, 86, 1358.

(53) Monkman, A. P.; Burrows, H. D.; Miguel, M. da G.; Hamblett, I.; Navaratnam, S. Synth. Met. 2001, 116, 75.

(54) Burrows, H. D.; Seixas de Melo, J.; Serpa, C.; Arnaut, L. G.; Miguel, M. da G.; Monkman, A. P.; Hamblett, I.; Navaratnam, S. Chem. Phys. 2002, 285, 3.

(55) Seixas de Melo, J.; Silva, L. M.; Arnaut, L. G.; Becker, R. S. J. Chem. Phys. 1999, 111, 5427.

(56) Burrows, H. D.; Seixas de Melo, J.; Forster, M.; Güntner, R.; Scherf, U.; Monkman, A. P.; Navaratnam, S. Chem. Phys. Lett. 2004, 305, 105. (57) Butler, J.; Hodgson, B. E.; Hoey, B. M.; Land, E. J.; Lea, J. S.; Lindley, E. J.; Rushton, F. A. P.; Swallow, A. J. Radiat. Phys. Chem. 1989, 34,633 .
(58) Serpa, C.; Arnaut, L. G. J. Phys. Chem. A 2000, 104, 11075

(59) Murov, S. L.; Carmichael, I.; Hug, G. L. Handbook of Photochemistry, second ed.; Marcel Dekker: New York, 1993.

(60) Bensasson, R. V.; Land, E. J.; Truscott, T. G. Excited States and Free Radicals in Biology and Medicine; Oxford University Press: Oxford, 1993.

(61) Keene, J. P.; Kessel, D.; Land, E. J.; Redmond, R. W.; Truscott, T. G. Photochem. Photobiol. 1986, 43, 117.

(62) Oliveros, E.; Suardi-Murasecco, P.; Aminian-Saghaffi, T.; Braun,

A. M.; Hansen, H.-J. Helv. Chim. Acta 1991, 74, 79.

(63) Pineiro, M.; Carvalho, A. L.; Pereira, M. M.; Rocha Gonsalves,

A. M. d'A.; Arnaut, L. G.; Formosinho, S. J. Chem.-Eur. J. 1998, 4, 2299

(64) Cooper, R.; Thomas, J. K. J. Chem. Phys. 1968, 48, 5097.

(65) Candeias, L. P.; Wildeman, J.; Hadziioannou, G.; Warman, J. M. J. Phys. Chem. B 2000, 104, 8366.

(66) Baxendale, J. H.; Fiti, M. J. Chem. Soc., Faraday Trans. 21972, 68,218

(67) Schmidt, W. F.; Allen, A. O. J. Chem. Phys. 1970, 52, 2350.

(68) Gee, N.; Freeman, G. R. Can. J. Chem. 1992, 70, 1618.

(69) Hoofman, R. J. O. M.; de Haas, M. P.; Siewbbeles, L. D. A.; Warman, J. M. Nature 1998, 392, 54.

(70) Grozema, F. C.; Siebbeles, F. D. A.; Warman, J. M.; Seki, S.;

Tagawa, S.; Scherf, U. Adv. Mater. 2002, 14, 228.

(71) Wasserberg, D.; Marsal, P.; Meskers, S. C. J.; Janssen, R. A. J.; Beljonne, D. J. Phys. Chem. B 2005, 109, 4410.

(72) Beljonne, D.; Shuai, Z.; Pourtois, G.; Bredas, J. L. J. Phys. Chem A 2001, 105, 3899 .

(73) Wasserberg, D.; Dudek, S. P.; Meskers, S. C. J.; Janssen, R. A. J. Chem. Phys. Lett. 2005, 411, 273.

(74) Monkman, A. P.; Burrows, H. D.; Hamblett, I.; Navaratnam, S.; Andersson, M. R. J. Chem. Phys. 2001, 115, 9046.

(75) Monkman, A. P.; Burrows, H. D. Synth. Met. 2004, 141, 81

(76) Köhler, A.; Beljonne, D. Adv. Funct. Mater. 2004, 14, 1.

(77) Köhler, A.; Wilson, J. S.; Friend, R. H.; Al-Suti, M. K.; Khan, M. S.; Gerhard, A.; Bässler, H. J. Chem. Phys. 2002, 116, 9457.

(78) Seixas de Melo, J.; Burrows, H. D.; Svensson, M.; Andersson, M. R.; Monkman, A. P. J. Chem. Phys. 2003, 118, 1550.

(79) Turro, N. J. Modern Molecular Photochemistry; University Science Books: Sausalito, CA, 1991.

(80) Pina, J.; Burrows, H. D.; Becker, R. S.; Dias, F. B.; Maçanita, A. L.; Seixas de Melo, J. J. Phys. Chem. B, in press. DOI: 10.1021/jp055455v. 